\title{
Molecular Dynamics Simulation of the Structure and Properties of Lithium Phosphate Glasses
}

Jian-jie Liang and Randall T. Cygan

Geochemistry Department

Sandia National Laboratories, Albuquerque, NM 87185-0750

Todd M. Alam

Department of Aging and Reliability, Bulk Materials

Sandia National Laboratories, Albuquerque, NM 87185-1407

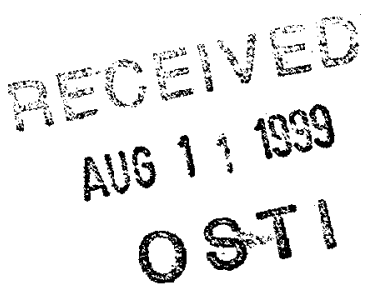

\section{Abstract:}

A new forcefield model was developed for modeling phosphate materials that have many important applications in the electronics and biomedical industries. Molecular dynamics simulations of a series of lithium phosphate glass compositions were performed using the new forcefield model. A high concentration of three member rings $\left(\mathrm{P}_{3} \mathrm{O}_{3}\right)$ was found in the glass of intermediate composition $\left(0.2 \mathrm{Li}_{2} \mathrm{O} \cdot 0.8 \mathrm{P}_{2} \mathrm{O}_{5}\right)$ that corresponds to the minimum in the glass transition temperature curve for the compositional series.

To be submitted to: Science 
Among the common glass-forming oxides (e.g. $\mathrm{SiO}_{2}, \mathrm{~B}_{2} \mathrm{O}_{3}$ ), phosphorous pentoxide $\left(\mathrm{P}_{2} \mathrm{O}_{5}\right)$ and its glass-formation process are the least understood. Yet, phosphate-based materials are important for a variety of applications. The low glasstransition temperature $\left(T_{g}\right)$ and high thermal-expansion coefficients of phosphate glasses make them candidate materials for glass-metal sealing applications (1), while desirable optical properties, such as the rare-earth stimulated-emission cross sections, low thermaloptical coefficients, and ultraviolet transparency, also make them important for laser glasses (2). Recent developments of novel compositions for fast-ion conductors (2), as well as uses in biomedical applications (3), have prompted further studies of phosphate glasses.

Knowledge of structure-property relationships is the key to tailoring phosphate materials for specific applications. However, in phosphate glasses, these relationships have not received adequate attention because of difficulties in materials preparation. Ultraphosphate glass compositions, with high $\mathrm{P}_{2} \mathrm{O}_{5}$ contents $\left(>50 \% \mathrm{P}_{2} \mathrm{O}_{5}\right)$ are highly hygroscopic, making preparation difficult, as well as presenting challenges in material characterization. Due to these difficulties, a relatively limited number of structural characterizations have been reported $(4,5)$, including $X$-ray and neutron scattering, Raman and IR spectroscopies, and solid state NMR studies. From these investigations, considerable progress has been made in understanding short-range and, to some extent, medium-range structures in phosphate glasses. However, a detailed understanding of certain composition-property relationships is lacking, for example, the strongly non-linear $T_{9}$-alkali content relationship observed experimentally in the alkali ultraphosphate solid solution series (5). Development of these relationships may prove critical for future material design.

Computational approaches have the advantage of bypassing many aspects of the experimental difficulties. In particular, molecular dynamics simulations can be used 


\section{DISCLAIMER}

This report was prepared as an account of work sponsored by an agency of the United States Government. Neither the United States Government nor any agency thereof, nor any of their employees, make any warranty, express or implied, or assumes any legal liability or responsibility for the accuracy, completeness, or usefulness of any information, apparatus, product, or process disclosed, or represents that its use would not infringe privately owned rights. Reference herein to any specific commercial product, process, or service by trade name, trademark, manufacturer, or otherwise does not necessarily constitute or imply its endorsement, recommendation, or favoring by the United States Government or any agency thereof. The views and opinions of authors expressed herein do not necessarily state or reflect those of the United States Government or any agency thereof. 


\section{DISCLAIMER}

Portions of this document may be illegible in electronic image products. Images are produced from the best available original document. 
effectively to relate physical properties to structural details within the glass. When a proper interatomic interaction model is established, structural details of the given system can be examined in any given scope (e.g. influence of alkali metal or alkali content on $T_{9}$ ). Such effort will build an important bridge between chemical composition, whose characteristics will be manifested in structural and dynamic properties, and certain property variations that are yet to be understood.

In molecular dynamic (MD) simulations, creating a reliable forcefield is the first and most important step in modeling the interatomic interactions that dictate the observational physical properties. In previous MD simulation of metal phosphate glasses (6), forcefield models considering primarily two-body interaction models have been used. These models explicitly incorporate electrostatic (Coulombic) and repulsive interactions to describe the iow? chemical bonding between neighboring atoms. They enjoy a certain level of success in simulating structures of meta- and pyrophosphate glasses (of the compositions, $M^{n+}{ }_{1 / n}$. $\mathrm{PO}_{3}$ and $\mathrm{M}_{2 \mathrm{n}}^{\mathrm{n}} \cdot \mathrm{PO}_{3}$, respectively; $\mathrm{M}$ is a metal ion of valence $\left.n+\right)$, in which the $\mathrm{PO}_{4}$ basic building units are less severely distorted. A potentially useful interaction model has also been proposed in a molecular mechanics simulation of phosphate biominerals $(7)$. In addition to the two-body interaction terms, three-body interactions involving O-P-O and PO-P angle-bendings were also included. Structural properties were reproduced reasonably well using this model. However, as this forcefield requires separate parameterizations when oxygen atoms are in different structural environments (terminal or non-bridging vs. bridging), manual identification of these different $O$ species is required. This leads to difficulties in MD simulations, particularly at high temperature where active bond breaking and bond reforming processes occur.

These difficulties in modeling phosphate chemistry stems from the outer-shell electron configuration of the $\mathrm{P}$ atom. Similar to $\mathrm{Si}, \mathrm{P}$ tends to form $s \mathrm{p}^{3}$ hybridization in 
phosphate compounds. As there are five valence electrons, the tetrahedrally hybridized orbitals are intrinsically anisotropic. This is particularly evident in the structure of phosphorous pentaoxide, $\mathrm{P}_{2} \mathrm{O}_{5}$. Among the four $\mathrm{P}-\mathrm{O}$ bonds associates with each $\mathrm{P}$ atom, three are bridging, $\mathrm{P}-\mathrm{O}_{\mathrm{b}}$, forming $-\mathrm{P}-\mathrm{O}-\mathrm{P}-$ connectivity, whereas the fourth constitutes the terminal $P=O$ bonds with a significant $\pi$-bond character. While the bond distances $(8)$ for the three $P-O_{b}$ are similar, between $1.56-1.60 \AA$, that of the $P=O$ bond is considerably shorter, in the range of $1.43 \sim 1.45 \AA$. These variations in $\mathrm{P}-\mathrm{O}$ bond lengths poses a serious challenge in the modeling of the material in two aspects. First, a forcefield needs to be constructed such that the asymmetry in the structure can be effectively handled; and second, a mechanism needs to be in place to distinguish the $P=O$ bond from the other $P$ $\mathrm{O}_{\mathrm{b}}$ bonds. This second aspect is especially important with high temperature simulations where the active bond breaking and reformation will dominate.

In the present work, we propose a forcefield model that describes explicit two- and three-body interactions, which is capable of distinguishing $P-O_{b}$ from $P=O$ bonding while simultaneously treating all the $\mathrm{O}$ atoms identically. A Lennard-Jones potential function was used to describe the short-range two-body interactions in addition to the usual Coulombic interaction. The following format of the Lennard-Jones potential was adopted

$$
E_{L J}=D_{0}\left[\left(\frac{r_{0}}{r}\right)^{12}-2\left(\frac{r_{0}}{r}\right)^{6}\right]
$$

in which $r$ represents interatomic distance, $r_{0}$ and $D_{0}$ are adjustable parameters.

The three-body terms include O-P-O and P-O-P interactions. The O-P-O term is to maintain the tetrahedral angles in the $\mathrm{PO}_{4}$ tetrahedra. It has the form

$$
E_{\text {angle }}=1 / 2 k_{0}\left(\theta-\theta_{0}\right)^{2}
$$


in which, $\theta$ is the actual O-P-O angle in the simulated structure, $\theta_{0}$ is the equilibrium tetrahedral angle of $109.47^{\circ}$, and $k_{0}$ is a parameter to be determined. The P-O-P term has the same analytical form as equation 2 except that the equilibrium angle, $\theta_{0}$, requires. parameterization.

Two known room temperature-stable structures of the $\mathrm{P}_{2} \mathrm{O}_{5}$ (orthorhombic) crystalline phases (8) were used in determining the unknown parameters in equations 1 and 2. The program GULP (9) was used in the parameter-fitting processes. The two structures of the $\mathrm{P}_{2} \mathrm{O}_{5}$ crystalline phases were used simultaneously in the fitting. The forcefield parameters were initially fitted using formal charges for each ion. However, while the model reproduced the structure of the crystalline phases well, it failed to provide valid thermodynamic values. It is known that phosphate compounds, like silicates, possess considerable covalent characteristics (10). Due to this strong covalent character, the effective ionic charges of the component atoms are effectively reduced. In a forcefield model, the electrostatic interaction is by far the most dominant force in holding the atoms together (accounts for over $90 \%$ of the total potential energy when formal charges are used to model the phosphate compounds). The use of formal charges will grossly exaggerate the binding energy of the system and fail to reproduce experimental thermodynamics values. One consequence is that glass-transition temperatures and melting temperatures are considerably overestimated in comparison to those observed (11). Therefore, in order to obtain reasonable thermodynamics parameters, such as $T_{g}$, it is critical to use partial effective charges in the MD simulation.

Effective ionic charges can be determined experimentally using high-resolution $\mathrm{X}$ ray diffraction (if the material is well crystallized). Alternatively, the charges can be. calculated in a first-principle molecular orbital calculation (10) of a cluster representation of 
the crystalline material. In their Harttree-Fork calculation of the electron structure of the $\mathrm{P}_{2} \mathrm{O}_{5}$ cluster, Uchino and Ogata found that all four O-atoms in a $\mathrm{PO}_{4}$ tetrahedron, be the individual $\mathrm{O}$-atom bridging or terminal, have very similar effective charge between -0.73 -0.87. This result provides some support that, ionically, the O-atoms in the $\mathrm{PO}_{4}$ tetrahedron are not vastly different. The difference between the bridging and terminal $\mathrm{O}$ atoms is absorbed in the covalent part of the corresponding bonds.

The effective charge of 1.85 as calculated for P-atom by Uchino and Ogata was adopted. The effective charge for $\mathrm{O}$-atom was calibrated to the effective $\mathrm{P}$ charge to be -0.74 to maintain electro-neutrality. This effective charge of the $\mathrm{O}$-atom corresponds to the lower margin of the calculated charges for the O-atoms in Uchino and Ogata's work. The effective charge for the Li metal was calculated accordingly to be 0.37 . Force field parameters were adjusted based on the reduced charges. The final fitted parameters are given in Table 1.

Forcefield model and parameters are also needed for the alkali metal. Only twobody interactions between the $\mathrm{Li}$ - and the O-atoms are considered, again using the Lennard-Jones potential model. In determining the Li-O interaction parameters, the structure (8) of a crystalline Li-metaphosphate, $\mathrm{LiPO}_{3}$, was used. The fitted parameters are included in Table 1.

Molecular dynamics simulations were preformed using the Cerius ${ }^{2}$ software package and the OFF energy program (Molecular Simulations Inc.). Six compositions in the solid solution series, $x \mathrm{Li}_{2} \mathrm{O} \cdot(1-\mathrm{x}) \mathrm{P}_{2} \mathrm{O}_{5}, \mathrm{x}=0.0,0.1,0.2,0.3,0.4$, and 0.5 , were considered. For any given composition in the series, a rectangular simulation box containing a total of 300 to 400 atoms was generated while maintaining a density as observed experimentally for similar composition. Periodic boundary conditions were applied to eliminate edge effects. The atomic positions were randomized, and the total energy of the simulation cell was minimized, using the forcefield model and 
parameterization developed in the present work. A molecular dynamics simulation using constant volume and temperature (NVT) canonical ensemble was then performed at 3000 $K$ where active melting was observed for all compositions under study. A thermal bath was used to maintain the temperature of the simulation cell using the Hoover (12) scheme. The Newtonian equation of motion was integrated for every one femtosecond time step. A total of 50000 steps of integration was used to equilibrate the system, corresponding to a total simulation length of $50 \mathrm{ps}$. During the simulation, atom connectivities were updated every 10 steps to ensure that active bond breaking and bond reforming processes be allowed while simultaneously two- and three-body interaction energies were calculated for each new configuration during the dynamic process. The system was then quenched from 3000 $\mathrm{K}$ to $300 \mathrm{~K}$ in $500 \mathrm{~K}$ intervals (the last step from $500 \mathrm{~K}$ to $300 \mathrm{~K}$ ). Each step lasting $7 \mathrm{ps,}$ corresponding to a quench rate of $\sim 7.1 \times 10^{11} \mathrm{~K} / \mathrm{s}$. Once at $300 \mathrm{~K}$, the system was equilibrated for an additional 50 ps.

As a test of the robustness of the forcefield model and the corresponding parameterization, the simulation of vitreous $\mathrm{P}_{2} \mathrm{O}_{5}$ was examined in detail. Under NVT condition at $300 \mathrm{~K}$, the system pressure and its variation over time is monitored, while the density of the glass was maintained at the experimentally observed value. The pressure fluctuation over a period of $50 \mathrm{ps}$ was essentially zero, indicating no stress at room temperature.

The validation of the forcefield model can also be determined by comparing the experimentally observed short-range structure, which is available for $\mathrm{P}_{2} \mathrm{O}_{5}$ crystals and glass, with those obtained through simulation. The short range P-O distance distribution can be represented using radial distribution function (RDF), which is essentially the probability of finding an atom at a give radial distance from the central atom. For the $\mathrm{P}_{2} \mathrm{O}_{5}$ crystalline phase that was simulated at $300 \mathrm{~K}$, the RDF for the first coordination sphere of the P-O atom pairs (Fig. 1a) clearly shows distinction of the shorter $P=O$ and the longer $P$ - 
$\mathrm{O}_{\mathrm{b}}$ bonds, in an abundance ratio of $1: 3$. The bond distance for the $P=O$ bond is $1.41 \AA$, as compared to the experimentally observed of $1.445-1.452 \AA$, whereas the average of the $\mathrm{P}-\mathrm{O}_{\mathrm{b}}$ bonds is $1.55 \AA$, comparable to the experimentally observed $1.562 \sim 1.583 \AA(8)$. In the quenched $\mathrm{P}_{2} \mathrm{O}_{5}$ glass, the $\mathrm{P}-\mathrm{O}$ distance distribution also shows a split (Fig. 1b) in the $P-O$ distance distribution, albeit the distinction is much more diffuse due to the amorphous nature of the system and the relatively fast quench rate. The average P-O distance is 1.57 $\AA$, comparable to the experimentally determined $1.58 \AA$ (5). The P-O-P angle of the $\mathrm{P}_{2} \mathrm{O}_{5}$ glass was also modeled well with the forcefield. The experimentally determined (5) P-O-P angle is $137 \pm 3^{\circ}$, while the simulated being $137^{\circ}$ (Fig. 1C).

One of the questions we tried to answer in our present simulation is what controls the non-linear $T_{g}$ variation as a function of composition of the alkali ultraphosphate glass, $x$ $\mathrm{Li}_{2} \mathrm{O} \cdot(1-\mathrm{x}) \mathrm{P}_{2} \mathrm{O}_{5}$. The glass-transition temperature can be determined by monitoring the volume-temperature relationship while keeping the pressure constant. This approach provides a computational analogue to the experimental determination of $T_{g} u s i n g$ dilotometry. A similar approach has been used in monitoring the $T_{g}$ variation in polymers (13). Figure $2 a$ shows the specific volume-temperature relationship simulated for the $\mathrm{P}_{2} \mathrm{O}_{5}$ glass as an NPT ensemble (constant pressure and temperature at each given temperature step). A slope change of the linearly-regressed $V$-T data indicates a $T_{9}$ of $628 \mathrm{~K}$ for the simulated system. This $T_{g}$ is close to the experimentally observed of $653 \mathrm{~K}(5)$. $T_{g}$ 's for the other glass compositions were determined similarly, and are plotted in Figure $2 \mathrm{~b}$. It can be seen that, although the simulated $T_{g}$ 's are in general lower than the experimentally observed ones, the overall trend of the experimentally observed (5) $T_{g}$ behavior was reproduced. Glass transition temperature at both ends of the solid solution series are relatively high, whereas at $-20 \% \mathrm{Li}_{2} \mathrm{O}$, a minimum in $\mathrm{T}_{9}$ is evident. 
The molecular-level controlling force behind $T_{g}$ behavior for phosphate glasses is puzzling and has been the subject of much debate. With the MD simulation results, it is possible to examine this behavior using the simulated glass structures, particularly from the medium-range structural point of view. Figure 3 shows a structural representation of the glass of composition $0.2 \mathrm{Li}_{2} \mathrm{O} \cdot 0.8 \mathrm{P}_{2} \mathrm{O}_{5}$. One of the unique structural features of this composition is the formation of 3-membered rings (rings formed by 3 corner-shared $\mathrm{PO}_{4}$ tetrahedra). In fact, this composition has by far the highest concentration of 3-membered rings (Fig. 4). Towards both ends of the solid solution series, the concentration of this 3membered ring decreases rapidly. Simultaneously, the ring size increases until chains dominate (Fig. 4 and Fig. 5). The highest concentration of 3-membered rings coincides with the lowest $T_{g}$ observed both experimentally and computationally for the composition of $0.2 \mathrm{Li}_{2} \mathrm{O} \cdot 0.8 \mathrm{P}_{2} \mathrm{O}_{5}$.

A recent Raman spectroscopic study (5) of equivalent compositions of phosphate glasses provides experimental evidence that supports the existence of ring-structures in the glass. For compositions with $10 \sim 35 \mathrm{~mol} \% \mathrm{Li}_{2} \mathrm{O}(x=0.10 \sim 0.35)$, high frequency shoulders were observed on the Raman lines of both the symmetric and asymmetric stretches of non-bridging P-O bonds. Their appearance on the high frequency side of the main stretching bands suggests strained structures. Similar features were found in borate and large surface area silicate glasses (14), and were, backed by high-level ab initial calculation (14), attributed to vibrationally-decoupled three- and four-member tetrahedral rings. Relative stability of different ring configurations in silicate glasses was recently examined using molecular orbital calculations (15). The heats of formation were found to become more negative (towards more stable configurations) as ring size grows from 2- to 6-memebers. This suggests that the glass composition that has the most abundant small rings is the least thermodynamically stable. The three-member ring is the smallest ring 
size revealed in the molecular dynamics simulation of the Li-phosphate glasses, and the composition, $0.2 \mathrm{Li}_{2} \mathrm{O} \cdot 0.8 \mathrm{P}_{2} \mathrm{O}_{5}$, has the highest abundance of such rings. This structural feature strongly correlates with the composition that corresponds to the lowest glass transition temperature.

The molecular dynamics simulations based on the new forcefield provide a strong molecular-based model for the interpretation of the structure and thermodynamic properties of phosphate glasses. The ability to obtain equilibrated glass structures and monitor their dilatancy at constant pressure provides a unique method for the characterization of glass formation temperatures. Furthermore, the occurrence of a stable phosphate ring structure at the minimum of the $T_{g}$ curve emphasizes the role of the alkali metal in controlling the structure and thermodynamic properties of the glass, and perhaps be used to predict structure-property relations and, ultimately, design new phosphate materials.

Sandia is a multiprogram laboratory operated by Sandia Corporation, a Lockheed Martin Company, for the United States Dipartmenl of Energy under contract DE-AC04-94AL 85000 . 


\section{References}

1. J. A. Wilder, J. Non-Crystalline Solids, 38/39, 879 (1980); R. K. Brow, L. Kovacic, R. E. Loehman, Ceram. Trans. 70, 177 (1996).

2. M. J. Weber, J. Non-Crystalline Solids, 123, 208 (1990); K. Kawamura, H. Hosono, H. Kawazoe, N. Matsunami, Y. Abe, J. Ceram. Soc. Japan, 104, 688

3. R.B. Heimann, T.A. Vu, M.L. Wayman, European J. Mineral., 9, 597 (1997).

4. U. Hoppe, G. Walter, R. Kranold, D. Stachel, Z. Naturforsch, 53a, 93 (1998); U. Hoppe, G. Walter, A. Barz, D. Stachel, A. C. Hannon, J. Phys: Condens. Matter, 10, 261 (1998).

5. J. J. Hudgens, R.K. Brow, D. R: Tallant, S. W. Martin, J. Non-Crystalline Solids, 223, 21 (1998); T. M. Alam, R. K. Brow, J. Non-Crystalline Solids, 223, 1 (1998).

6. G. Cormier, J. A. Capobianco, A. Monteil, J. Non-Crystalline Solids, 168, 115 (1994); G. Cormier, J. A. Capobianco, and C. A. Morrison, J. Chem. Soc. Faraday Trans., 90, 755 (1994); G. G. Boiko, N. S. Andreev, A. V. Parkachev, J. Non-Crystalline Solids, $238,175(1998)$.

7. M. G. Taylor, K. Simkiss, M. Leslie, J. Chem. Soc. Faraday Trans., 90, 641 (1994)

8. El H. Arbib, B. Elouadi, J. P. Chaminade, J. Darriet, J. Solid State Chem., 127, 350 (1996); D. Stachel, I. Svoboda, H. Fuess, Acta Crystallogr., C51, 1049 (1995); R. W. G. Wyckoff, Crystal Structures (Interscience Publishers, New York, 1963); J. C. Par, I. Tordjman, Acta Cryst., B32, 2960 (1976).

9. J. D. Gale, General Utility Lattice Program, developed at the Royal Institution of Great Britain/Imperial College, 1992-4.

10. T. Uchino, Y. Ogata, J. Non-Crystalline Solids, 181, 175 (1995); P. C. Harkins, G. Petersson, P. Haake, J. Inorg. Biochem., 61, 25.(1996). 
11. B. Vessal, M. Amini, D. Fincham, C. R. A. Catlow, Philosophical Magazine B-Physics Of Condensed Matter Structural Electronic Optical And Magnetic Properties, 60, 753 (1989).

12. W. H. Hoover, Phys. Rev. A, 31, 1965 (1985).

13. R. J. Roe, Adv. Polymer Sci., 116, 111 (1994).

14. A. K. Hassan, L. M. Torrell, L. Borjesson, H. Doweider, Phys. Rev., B45, 12797 (1992); F. L. Galeener, R. A. Barrio, E. Martinez, R. J. Elliot, Phys. Rev. Lett., 53, 2429 (1984); T. Uchino, Y. Tokuda, T. Yoko, Physical Review, B58, 5322 (1998).

15. L. L. Hench, J. K. West, Annu. Rev. Mater. Sci., 25, 37 (1995).

16. Acknowledgement: The authors would like to acknowledge the support of the U.S. Department of Energy, Office of Basic Energy Sciences, Materials Science Research. Richard Brow provided invaluable support and guidance during the early stages of this project. 


\section{Figure captions}

Figure 1. Interatomic distances and angles simulated for the $\mathrm{P}_{2} \mathrm{O}_{5}$ crystalline and glass phases. a: Radial distribution function (RDF) of $\mathrm{P}-\mathrm{O}$ atom pair in the $\mathrm{P}_{2} \mathrm{O}_{5}$ crystalline phase; b: RDF of $\mathrm{P}-\mathrm{O}$ atom pair in the $\mathrm{P}_{2} \mathrm{O}_{5}$ glass phase; $\mathrm{c}$ : bond-angle distribution in the $\mathrm{P}_{2} \mathrm{O}_{5}$ glass phase.

Figure 2. Glass-transition temperature $\left(T_{g}\right)$ in the lithium phosphate glass, $x \mathrm{Li}_{2} \mathrm{O} \cdot(1-x)$ $\mathrm{P}_{2} \mathrm{O}_{5}$. a. Volume-temperature relationship of the simulated $\mathrm{P}_{2} \mathrm{O}_{5}$ glass; b. Variation of $T_{9}$ as a function of composition. Solid circle: simulated; open circle: experimentally observed (4).

Figure 3. Structure of the glass composition, $0.2 \mathrm{Li}_{2} \mathrm{O} \cdot 0.8 \mathrm{P}_{2} \mathrm{O}_{5}$. Notice the 3-member rings (some of them highlighted in green; see the enlarged representation in the inset) in the structure. Purple $=\mathrm{P} ;$ red $=0$; yellow $=\mathrm{Li}$.

Figure 4. Distribution of the abundance of various sized rings as a function of composition in the alkali phosphate glass, $x \mathrm{Li}_{2} \mathrm{O} \cdot(1-x) \mathrm{P}_{2} \mathrm{O}_{5}$.

Figure 5. Glass structure of the end-member compositions of the alkali phosphate glass, $x$ $\mathrm{Li}_{2} \mathrm{O} \cdot(1-\mathrm{x}) \mathrm{P}_{2} \mathrm{O}_{5} . \mathrm{a}: \mathrm{x}=0.0 ; \mathrm{b}: \mathrm{x}=0.5$. Purple $=\mathrm{P} ;$ red $=\mathrm{O} ;$ yellow $=\mathrm{Li}$. Notice the dominance of chains in the structure (one of the chains being highlighted in green in each picture). 
Table I. Force field parameters determined empirically. See text for definition of the parameters.

\begin{tabular}{lll}
\hline $\begin{array}{l}\text { Two-body } \\
\text { Interaction }\end{array}$ & $D_{0}(\mathrm{eV})$ & $\Gamma_{0}(\AA)$ \\
\hline$P^{1.85}-\mathrm{O}^{-0.74}$ & 0.004251 & 2.1550 \\
$O^{-0.74}-O^{-0.74}$ & 0.012185 & 3.2743 \\
$L^{0.37}-O^{-0.74}$ & 0.0006680 & 2.8890 \\
& & \\
Three-body & $k_{0}\left(\mathrm{eV} / \mathrm{rad}^{2}\right)$ & $\theta_{0}\left(^{\circ}\right)$ \\
Interaction & & \\
\hline & 3.5401 & 109.47 \\
$O-P-O$ & 20.9326 & 135.58 \\
\hline
\end{tabular}




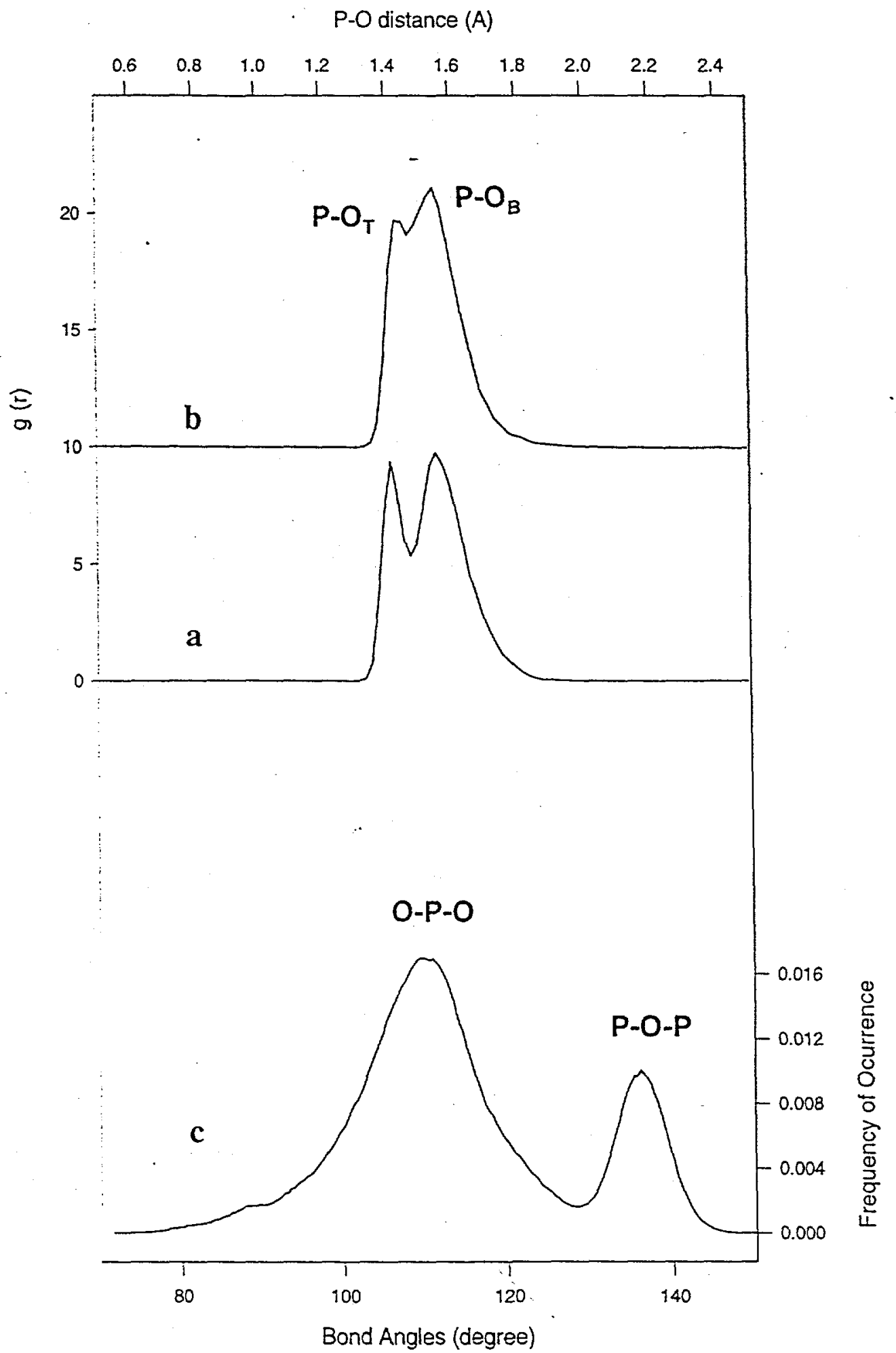


a

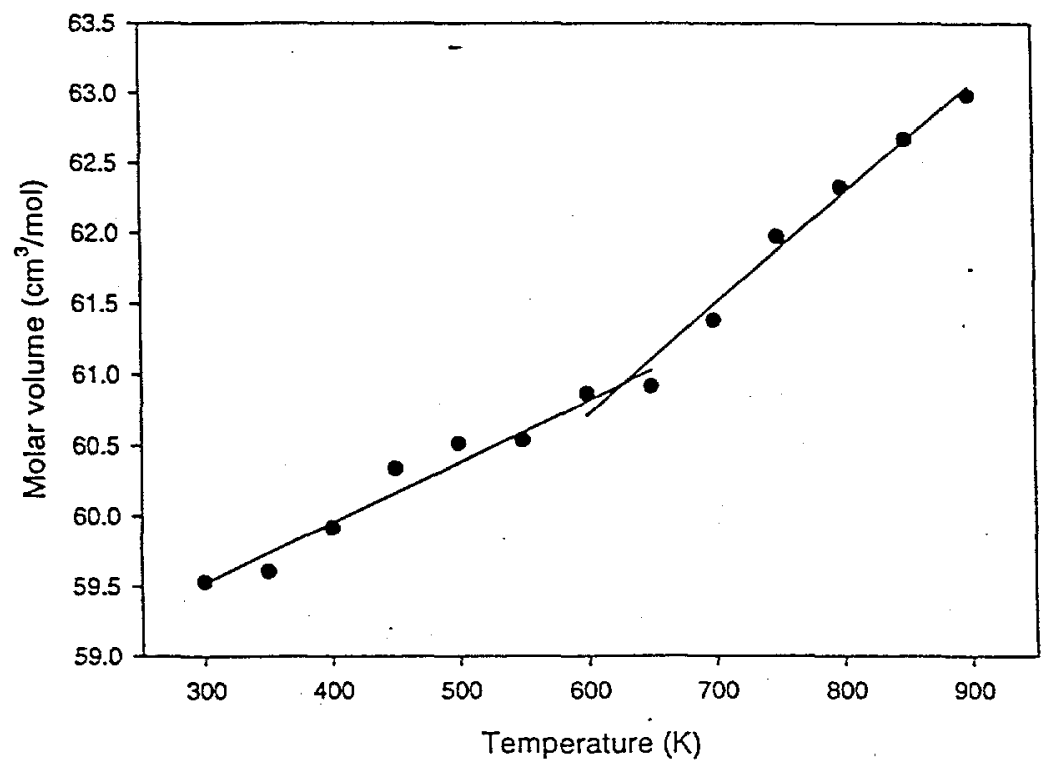

b

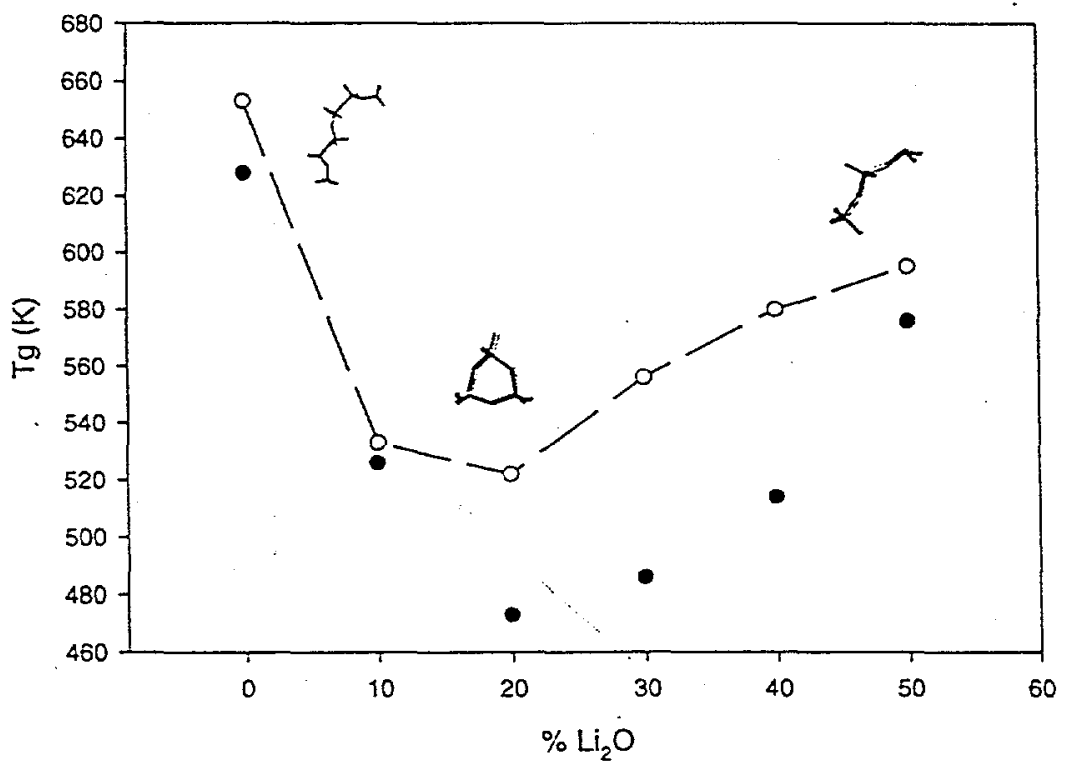




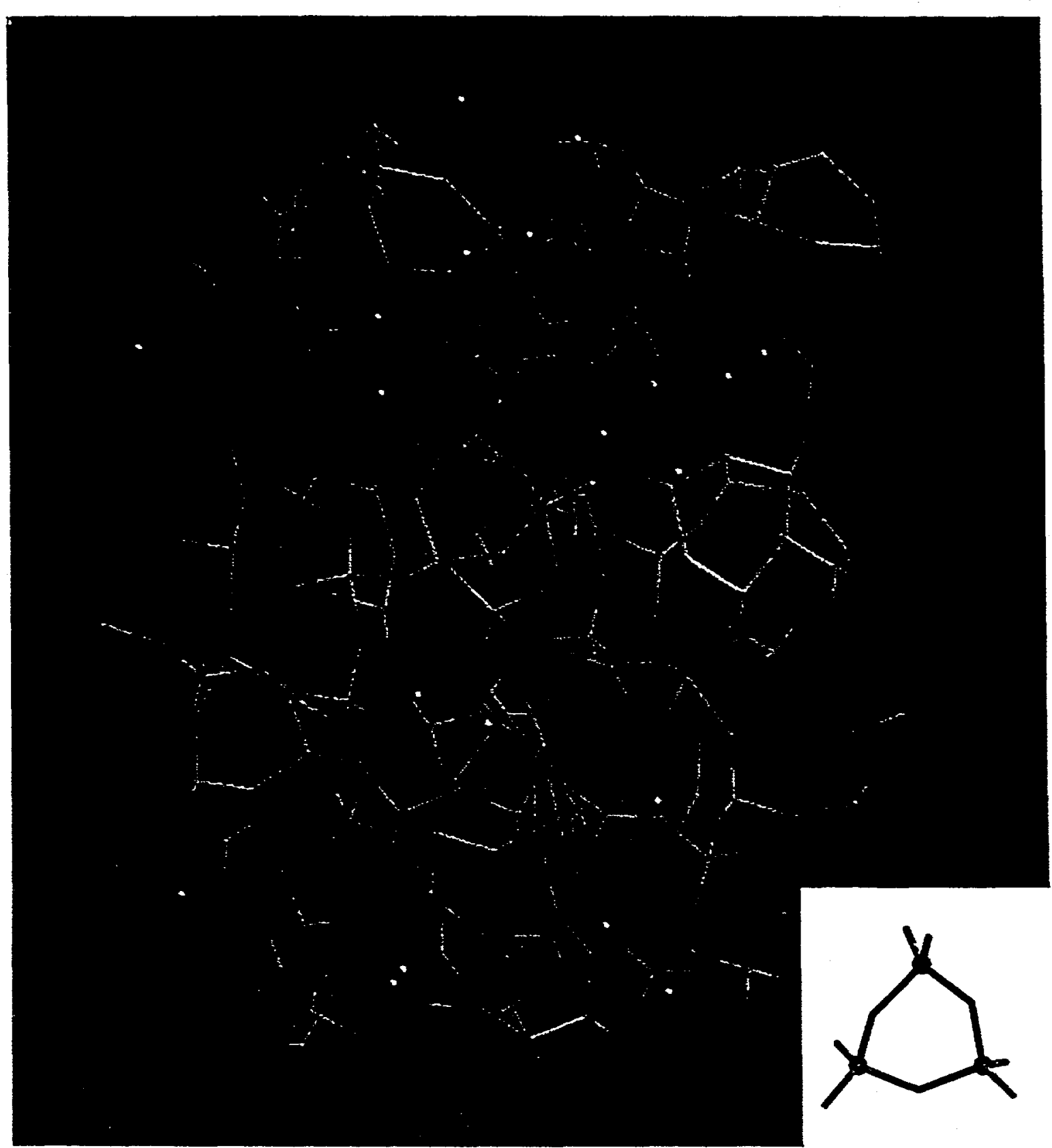




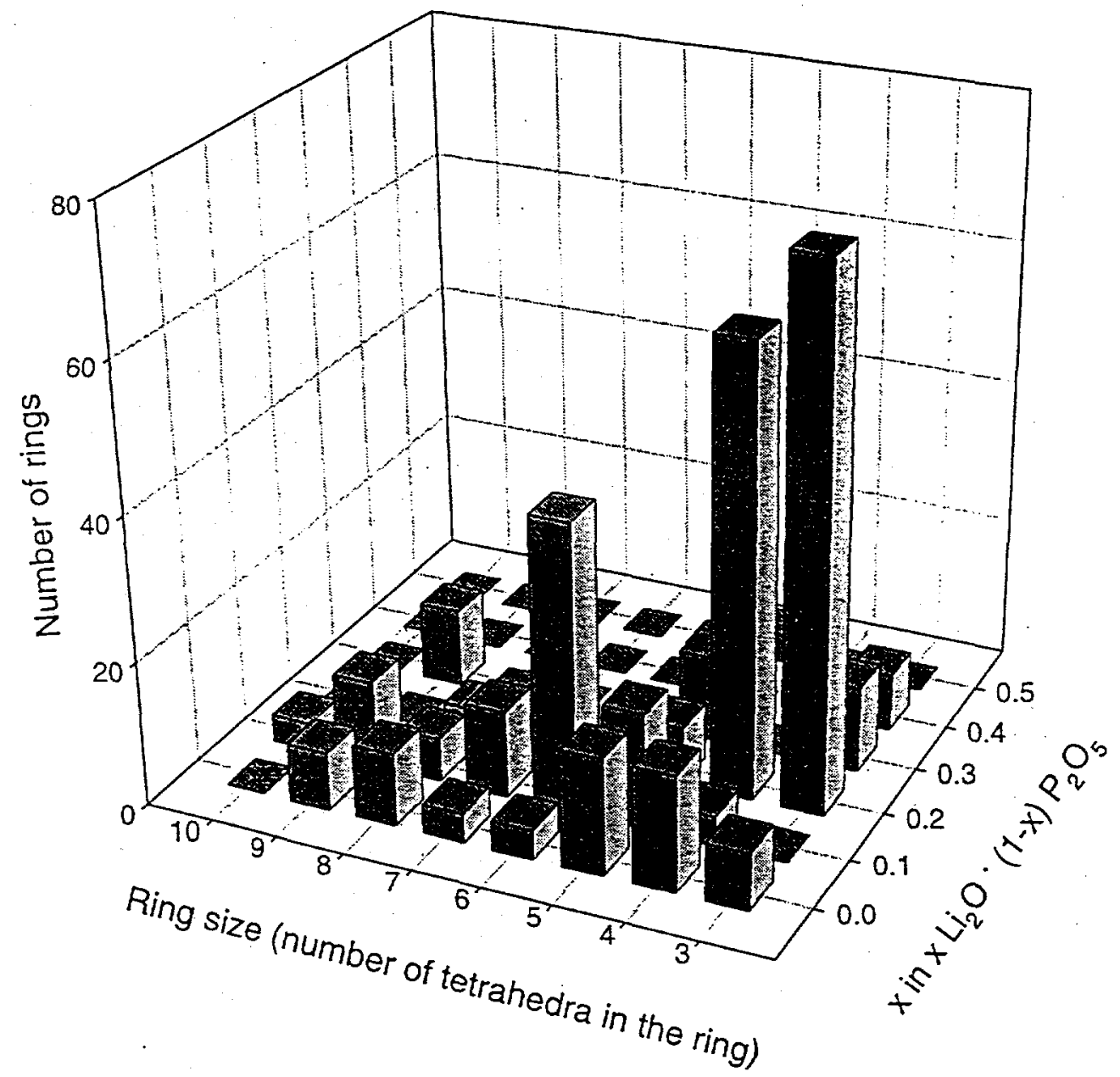




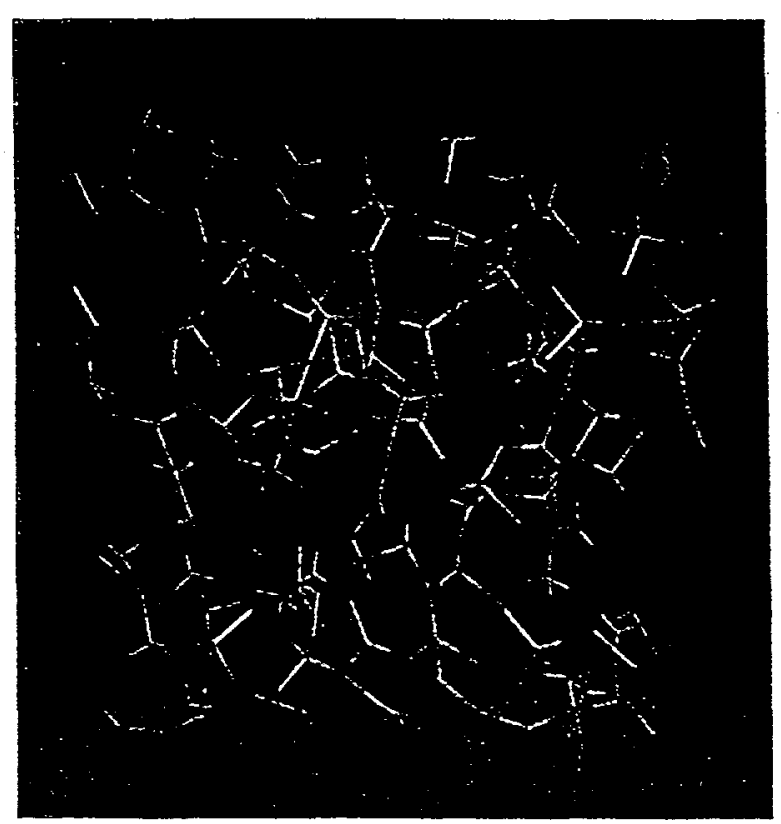

a

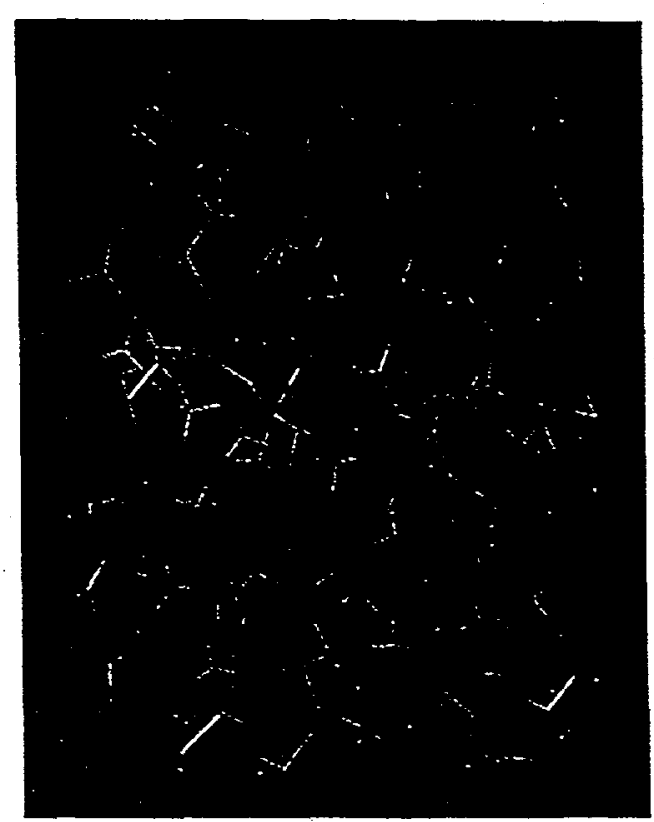

b 